\title{
Formulation development of topical antibacterial lotion with Theobroma cacao pod husk ash extract for treatment of shaving bumps
}

\begin{abstract}
The aims of this study were to determine the emulsifying properties of Theobroma cacao pod husk ash (CPHA) methanolic extract combined with shea butter and explore the antibacterial activities and physicochemical characteristics of resulting emulsions toward the development of a topical antibacterial lotion formulation for shaving bumps treatment. The ash resulting from combustion of pod husks of freshly harvested ripe cocoa fruits was extracted with methanol and the extract evaporated to dryness. Shea butter was also extracted by traditional method from kernels from the shea tree. These natural-source materials were combined with pharmaceutical ingredients (buffer, viscosity enhancer, preservative) to develop fluid emulsion formulations. Stability characteristics (droplet size, viscosity, creaming, and $\mathrm{pH}$ ) of the formulations were evaluated as well as their antibacterial activities against microorganisms isolated from after-shave bump swabs of adult male volunteers and against reference organisms; in order to select product(s) of best qualities suitable as shaving bumps medication. The prototype formulations exhibited suitable physicochemical properties and demonstrated inhibitory activities against several isolated shaving bump microbes and the reference organisms namely, Staphylococcus aureus, Bacillus subtilis and Pseudomonas aeruginosa. Two formulations were finally selected as having physicochemical and antibacterial qualities most suitable for shaving bumps therapy, which contained shea butter $(20 \%)$, citrate buffer $(5 \%)$, and parabens $(0.3 \%)$, prepared using $5 \%$ CPHA extract solution with and without methyl cellulose $(2 \%)$, respectively. The novel shea butter-incorporated emulsion-lotion formulations of CPHA extract provide a useful therapeutic option of topical medication for the treatment of shaving bumps in men.
\end{abstract}

Keywords: Theobroma cacao, cocoa pod husk ash extract, lotion formulation, antibacterial activity, shaving bumps treatmen
Volume 10 Issue | - 202 |

\author{
Hannah O Akinrotohun, Ayobami O \\ Oyedele, Oluwatoyin A Igbeneghu, Lara O \\ Orafidiya \\ Department of Pharmaceutics, Faculty of Pharmacy, Obafemi \\ Awolowo University, Ile-lfe Nigeria
}

Correspondence: Hannah O Akinrotohun, Department of Pharmaceutics, Faculty of Pharmacy, Obafemi Awolowo University, lle-Ife Nigeria, Tel +44 7768908359 ,

Email gbemihannaholu@yahoo.com

Received: December 28, 2020 | Published: February II, 202
Abbreviations: PFB, pseudofolliculitis barbae; CPHA, T cacao pod husk ash

\section{Introduction}

Shaving bumps, Pseudofolliculitis barbae (PFB), are an inflammatory disorder of follicular and peri-follicular skin resulting from ingrown hairs, which occur most commonly in the beard areas of men, are cosmetically disfiguring and may be psychologically distressing for affected persons. PFB is caused by the shaving of terminal hair in genetically predisposed persons with tight curly hair curved with its concavity toward the epidermis. ${ }^{1}$ After a close shave, emerging sharp-tipped hairs from the follicle grow downwards or parallel to the skin and penetrate the skin (dermis or epidermis) a short distance away from the follicle, called extra-follicular penetration. Such hair-shaft invagination of the dermis or epidermis causes a foreign body reaction manifest as follicular or peri-follicular papules or pustules. In cases where the hair has been pulled before cutting, by shaving against the grain or stretching the skin, the sharp tip of cut hair may retract into the follicle and penetrate the follicular wall underneath the skin (trans-follicular penetration) to produce foreign body reaction. ${ }^{2}$ PFB has been linked to the use of various instruments for shaving, especially multi-blade razors, as well as to improper razor use in shaving techniques such as the use of blunt blades or shaving against the grain that may increase the chance of trans-follicular penetration. Other causative links are: dry shaving (not moisturizing the hair before shaving) thus producing sharp beveled tips that encourage extra-follicular penetration, infrequent shaving that allows hair growth to a length that leads to penetration, and plucking of hair by various means that leave behind hair fragments under the skin, causing inflammatory reactions. ${ }^{3,4}$

Therapeutic objectives for PFB management include managing ongoing inflammation and its complications and preventing the development of new lesions. Patients presenting with moderate to severe inflammations are treated with topical anti-inflammatory and antibiotic medications, which reduce inflammation by reducing contamination by the normal skin flora that may contribute to inflammation, and also prevent the development of secondary infection. ${ }^{2}$ Shea butter is the natural fat obtained by extraction from seeds of the tree, Vitellaria paradoxa C.F. Gaertner, family Sapotaceae, indigenous to the East, West and Central African subregions, ${ }^{5}$ which has been used in the preparation of cosmetics and skin care products for decades. ${ }^{6,7}$ It has demonstrated emollient property in eczema treatment ${ }^{8}$ and is well suited on human skin in topical products. ${ }^{9}$ Theobroma cacao L. or cocoa (family Sterculiaceae) is similarly an important agricultural and economic crop that grows in several tropical areas namely, West Africa, South America and Central America ${ }^{10}$ Following the removal of cocoa beans (the main economic part of cocoa pods, used for chocolate manufacture), large quantities 
of cocoa pod husks are left as a by-product largely underexploited. However, studies have been reported on prospective pharmaceutical applications of $T$. cacao pod husk including its use as an excipient, ${ }^{11}$ for the production of tablets, ${ }^{12,13}$ the use of its chromatographyseparated extracts as antiwrinkle agents for human $\operatorname{skin}^{14,15}$ and, more recently the methanolic and aqueous extracts of $T$. cacao pod husk ash (CPHA) were adjudged suitable for use as pharmaceutical ingredients through demonstrating appropriate physicochemical and antimicrobial properties. ${ }^{16}$ In view of the identified pharmaceutical use potential of CPHA extracts, therefore, the present work has been carried out to determine the extracts' emulsifying properties, evaluate and explore the antibacterial activities of resulting emulsion products in combination with shea butter, for the development of a topical antibacterial lotion formulation useful for prospective treatment of after-shave bumps.

\section{Materials and methods}

\section{Ethical clearance}

This study was approved by the Ethics and Research Committee of Obafemi Awolowo University Teaching Hospitals Complex Ile-Ife Nigeria, and given ethical clearance certificate numbers: NHREC/27/02/2009a (national) and IRB/IEC/0004553 (international).

\section{Collection, authentication, ashing of T. cacao (cocoa) pod husk and extraction of ash}

Freshly harvested, ripe cocoa (T. cacao L.) pods were procured from cocoa farmers residing in Ile-Ife Nigeria. A specimen of the cocoa pod and leaves was prepared, authenticated, assigned the catalogue number IFE 17464 and deposited at the Ife Herbarium, Department of Botany, Obafemi Awolowo University (OAU), Ile-Ife Nigeria. Following removal of the beans, the broken cocoa pods were washed, sun-dried for 14 days, turning them over constantly to hasten the drying process. They were further dried in an hot-air oven (at 45 ${ }^{\circ} \mathrm{C}$ ) to a moisture content of about $10 \%$, cut into smaller pieces and then burned in a furnace at $500{ }^{\circ} \mathrm{C}$ over $6 \mathrm{~h}$ to produce cocoa pod husk ash (CPHA). The ash was collected, weighed and extracted with methanol and water, respectively, as previously described. ${ }^{16}$

\section{Extraction of shea butter from shea kernels}

Kernels of the shea tree were procured from indigenous market in Shaki, Oyo State Nigeria, oven-dried in the laboratory (at $45^{\circ} \mathrm{C}$ ) and broken to separate the nuts from their shells. The nuts were ground and kneaded in a porcelain mortar with pestle to liberate shea fat from the nut pulp mass. The frothy oily mass was washed with water to remove dirt particles, scooped into a pot and boiled until neat shea oil separated, floating on top of aqueous sediment. The shea oil was collected by decantation and filtered through a Whatman No. 1 filter paper in an oven at $60^{\circ} \mathrm{C}$; and congealed as neat shea butter on cooling at the ambient temperature.

\section{Formulation studies}

Preliminary emulsion formulations were prepared to study the emulsifying ability of cocoa pod husk ash (CPHA) aqueous and methanolic extracts as providers of alkali to react with fatty acids contained in shea butter; and to determine the shea butter quantity required to give liquid emulsions. Triplicate preliminary formulation (PF) samples were made having composition as given in Table 1, prepared with the CPHA aqueous extract $(4 \% \mathrm{w} / \mathrm{v}$ solution) and with the methanolic extract (2.5 and $5.0 \% \mathrm{w} / \mathrm{v}$ concentrations), respectively, as the alkali-containing aqueous phase. The aqueous phase, also containing $0.2 \%$ methyl and $0.1 \%$ propyl parabens, was heated to $70{ }^{\circ} \mathrm{C}$ and added to shea butter (oil phase) previously heated to $60{ }^{\circ} \mathrm{C}$ and placed in a $100 \mathrm{ml}$ screw-cap glass bottle, and shaken vigorously with intermittent rest periods until cool. Other emulsion formulations prepared (PF 9-14; Table 1) contained, in addition, emulsifiers - Tween 80 and Span 80 at a ratio of 6.3:3.7 (w/w), respectively. The Tween 80 was added to the aqueous phase and Span 80 to the oil phase before the two phases were heated. All the emulsion formulations were stored on the shelf (ambient temperature: $29 \pm 2{ }^{\circ} \mathrm{C}$ ) for 7 days and observed daily for consistency, pourability, creaming, redispersibility after creaming as well as cracking.

Table I Composition and physical stability characteristics of preliminary emulsion formulations of Theobroma cacao pod husk ash (CPHA) extracts containing shea butter

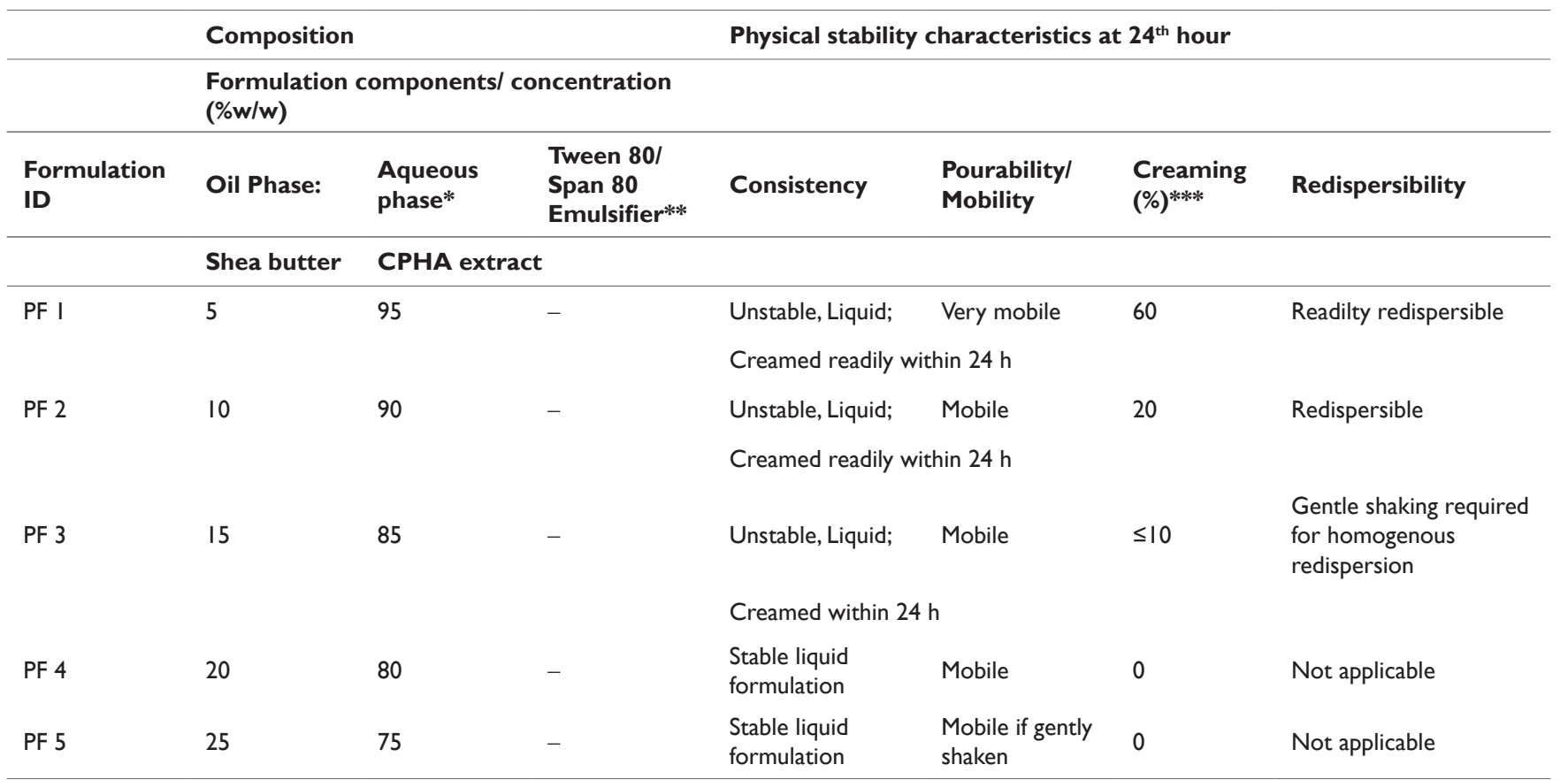


Table Continued...

Composition $\quad$ Physical stability characteristics at $24^{\text {th }}$ hour

Formulation components/ concentration

(\%w/w)

\begin{tabular}{|c|c|c|c|c|c|c|c|}
\hline $\begin{array}{l}\text { Formulation } \\
\text { ID }\end{array}$ & Oil Phase: & $\begin{array}{l}\text { Aqueous } \\
\text { phase* }\end{array}$ & $\begin{array}{l}\text { Tween } \mathbf{8 0 /} \\
\text { Span } \mathbf{8 0} \\
\text { Emulsifier** }\end{array}$ & Consistency & $\begin{array}{l}\text { Pourability/ } \\
\text { Mobility }\end{array}$ & $\begin{array}{l}\text { Creaming } \\
(\%)^{* * *}\end{array}$ & Redispersibility \\
\hline PF 6 & 30 & 70 & - & $\begin{array}{l}\text { Liquid or } \\
\text { semisolid } \\
\text { consistency } \\
\text { depending on } \\
\text { handling }\end{array}$ & Immobile & $\leq 10$ & $\begin{array}{l}\text { Vigorous shaking } \\
\text { required for } \\
\text { homogenous } \\
\text { redispersion }\end{array}$ \\
\hline PF 7 & 35 & 65 & - & $\begin{array}{l}\text { Semisolid or } \\
\text { solid at ambient } \\
\text { temperature }\end{array}$ & Immobile & $\leq 10$ & $\begin{array}{l}\text { Vigorous shaking } \\
\text { required for } \\
\text { homogenous } \\
\text { redispersion }\end{array}$ \\
\hline PF 8 & 40 & 60 & - & Solid consistency & Immobile & 0 & Solidified \\
\hline PF 9 & 20 & 77.5 & 2.5 & $\begin{array}{l}\text { Stable liquid } \\
\text { formulation }\end{array}$ & Pourable & 50 & Redispersible \\
\hline PF 10 & 25 & 72.5 & 2.5 & $\begin{array}{l}\text { Stable liquid } \\
\text { formulation }\end{array}$ & Pourable & 30 & $\begin{array}{l}\text { Vigorous shaking } \\
\text { required for } \\
\text { homogenous } \\
\text { redispersion }\end{array}$ \\
\hline PF II & 30 & 67.5 & 2.5 & Viscous liquid & $\begin{array}{l}\text { Hardly } \\
\text { pourable }\end{array}$ & 20 & Not redispersible \\
\hline PF 12 & 30 & 65 & 5 & Semisolid & Immobile & 20 & Solidified \\
\hline PF I3 & 30 & 62.5 & 7.5 & $\begin{array}{l}\text { Semisolid; } \\
\text { Cracked }\end{array}$ & $\begin{array}{l}\text { Immobile; } \\
\text { Cracked }\end{array}$ & 0 & Solidified; Cracked \\
\hline PF I4 & 30 & 60 & 10 & Semisolid & Immobile & 0 & Solidified \\
\hline
\end{tabular}

Key:

Formulation ID: Identity codes of preliminary emulsion formulations

PF: A preliminary formulation of CPHA-extract emulsion

*The aqueous phase, CPHA-extract solution containing methanolic extract $(2.5,5.0 \% \mathrm{w} / \mathrm{v})$ or aqueous extract $(4.0 \% \mathrm{w} / \mathrm{v})$, was used in replicated experiments. Antimicrobial preservative (methyl paraben $0.2 \% \mathrm{w} / \mathrm{v}$ combined with propyl paraben $0.1 \% \mathrm{w} / \mathrm{v}$ ) was included also

**The emulsifier consisted of Tween 80 and Span 80 combined in a 6.3:3.7 (w/w) ratio

*** Creaming data indicates the cream-phase volume ratio, CVR (Vu/Vo) converted to percentage (\%) unit

-Ingredient (emulsifying agent) was absent in the sample formula so indicated

$0 \%$ Creaming means, no creaming occurred in the pre-formulation samples

Arising from observations of the preliminary emulsion formulation series, another set (A, B, C, and D; Table 2) was prepared and studied in order to select a lotion (emulsion) formulation that would be suitable as topical application for the control of shaving bump. The latter set of formulations contained $20 \% \mathrm{w} / \mathrm{w}$ shea butter (oil phase), differing concentrations $(2.5$ or $5 \% \mathrm{w} / \mathrm{v})$ of the methanolic CPHA extract solution (aqueous phase), and preservatives $(0.2 \%$ methyl and $0.1 \%$ propyl parabens); while some (B, C, and D) contained citrate buffer in order to moderate $\mathrm{pH}$ of the preparation to about the neutral value (7.0). Methyl cellulose (MC; 2 or $3 \% \mathrm{w} / \mathrm{v})$ was incorporated into some of the preparations as a viscosity-imparting agent. These products, stored on shelf $\left(29 \pm 2{ }^{\circ} \mathrm{C}\right)$, were studied for $\mathrm{pH}$, viscosity, creaming profile and droplet size analysis after Day 1 and Weeks 1 , 2 , and 4, respectively. $\mathrm{pH}$ was determined with a digital $\mathrm{pH}$ meter (HM Digital Inc., California, USA); viscosity measurements were carried out using the Rion VT-04 viscotester (Rion Co. Ltd, Tokyo);

creaming profile was determined from duplicate $10 \mathrm{ml}$ samples in stoppered $10-\mathrm{ml}$ calibrated test tubes, and droplet size analysis carried out with a microscope as previously described. ${ }^{17}$ Accelerated stability study was carried out on the lotion formulations by evaluating the effect of centrifugation (1000 or 5000 revolutions per minute; rpm) on duplicate $5 \mathrm{ml}$ samples placed in centrifuge bottles over 10, 30, or $60 \mathrm{~min}$. Two of the formulations (B and C), which demonstrated more desirable qualities than others in course of the experiments, were also evaluated for the effect of freeze-thaw temperature cycling on their stability indicators (droplet size, viscosity and $\mathrm{pH}$ ), by storing duplicate $50 \mathrm{ml}$ samples first at $-5^{\circ} \mathrm{C}$ (in a freezer) for 3 days and then transferred into an oven maintained at $44{ }^{\circ} \mathrm{C}$ for another 3 days. This freeze-thaw temperature cycling was repeated for 5 cycles (30 days), after which the lotion samples were restored to room temperature $\left(29 \pm 2^{\circ} \mathrm{C}\right)$ for $24 \mathrm{~h}$, and their resultant stability qualities determined. 
Table 2 Composition of lotion formulations of Theobroma cacao pod husk ash (CPHA) extract

\begin{tabular}{lllll}
\hline & \multicolumn{4}{c}{$\begin{array}{l}\text { Formulation ID/ Components' } \\
\text { concentration }\end{array}$} \\
\hline Components a & A & B & C & D \\
\hline Oil Phase: & 20 & 20 & 20 & 20 \\
Shea butter (\%w/w) & & & & \\
Aqueous phase & 2.5 & 5 & 5 & 5 \\
(Dispersion medium): & & & & \\
CPHA extract $(\% \mathrm{w} / \mathrm{v}) \mathrm{b}$ & & & & \\
Citrate buffer $(\% \mathrm{w} / \mathrm{v}) \mathrm{c}$ & - & 5 & 5 & 5 \\
Methyl cellulose $(\% \mathrm{w} / \mathrm{v})$ & - & - & 2 & 3 \\
Methyl paraben $(\% \mathrm{w} / \mathrm{v})$ & 0.2 & 0.2 & 0.2 & 0.2 \\
Propyl paraben $(\% \mathrm{w} / \mathrm{v})$ & 0.1 & 0.1 & 0.1 & 0.1 \\
\hline
\end{tabular}

Key:

Formulation ID: Identity codes of lotion formulations

a: Concentration parameters of the components are in parenthesis

b: Values indicate concentration of methanolic CPHA extract in the dispersion medium (aqueous phase)

c: The citrate buffer $(\mathrm{pH} 4.0)$ consisted of two ingredients: citric acid monohydrate and trisodium citrate at 1.5 and $3.5 \% \mathrm{w} / \mathrm{v}$, respectively

- Ingredient so indicated was absent in the lotion formula

\section{Collection of volunteers' after-shave bump swabs}

Using sterile swab sticks moistened with sterile water, aftershave bump swab of the beard area of each of 15 male adult volunteers aged between 25 and 40 years was collected aseptically in accordance with the approved study protocol. All the volunteer participants in the study were graduate or undergraduate students of the Obafemi Awolowo University (OAU), Ile-Ife Nigeria. Informed consent of each participant was appropriately obtained prior to their participation. Each participant filled a questionnaire that documented their individual data, namely: age, shaving history, frequency, method and equipment, after-shave signs and symptoms. Participants having after-shave bumps at the time of sampling, who were not using and had not used any after-shave preparation for two weeks prior to the sample collection, and were not on any antibiotic or anti-inflammatory medication and did not have any visible sign of topical (facial skin) fungal infection, met the inclusion criteria for the study.

\section{Studies on microbes isolated from after-shave bump swab}

The bump swab samples from volunteers were individually plated within $1 \mathrm{~h}$ of collection to obtain pure microbial colonies on nutrient agar and Sabouraud dextrose agar plates and incubated at 37 ${ }^{\circ} \mathrm{C}$ and $25^{\circ} \mathrm{C}$, respectively, code-numbering the plates such that the resultant isolates were linkable to the code-identity of each volunteer, respectively. Colonies growing on the plates within 24 to $48 \mathrm{~h}$ of incubation for bacteria and within 5 days for fungi were subcultured aseptically onto fresh plates of mannitol salt agar and nutrient agar for bacterial growth and Sabouraud dextrose agar for yeast or fungal growth. All the pure isolates resulting from the subcultures were then preserved in cryopreservation medium in cryovials (Nalgene, Rochester NY, USA) stored at $-4{ }^{\circ} \mathrm{C},{ }^{18}$ until needed for determination and evaluation. Each isolate was recovered from cryovial storage with a sterile inoculating loop and subcultured onto nutrient agar, mannitol salt agar (for bacteria) and on Sabouraud dextrose agar plates (for yeast/fungi) and incubated at 37 and $25^{\circ} \mathrm{C}$ for $24-48 \mathrm{~h}$, as appropriate for bacterial and yeast/fungal growth, to produce isolated colonies, respectively. The morphological characteristics of the colonies produced by each revived isolate on the respective media (colour, average size, margin configuration, surface elevation and consistency) were noted, and the Gram-stain reaction of each facial swab isolate was determined, using the pure cultures of Escherichia coli ATCC 25922 and Staphylococcus aureus NCTC 6571 as the Gram-negative and Gram-positive controls, respectively. Biochemical tests were also carried out for further identification of the recovered facial swab isolates (namely: catalase test, slide and tube coagulase tests, and the modified oxidase test) in order to distinguish between micrococci and staphylococci, ${ }^{19}$ following the standard methods described by Barrow and Feltham, ${ }^{20}$ using Pseudomonas aeruginosa ATCC 10145 and E. coli ATCC 25922 as the positive and negative controls, respectively.

\section{Antibiotic susceptibility testing of microbes isolated from after-shave bump}

The bacterial isolates were tested for their susceptibilities to 3 antibiotics namely: ciprofloxacin $(5 \mu \mathrm{g})$ (Cypress Diagnostics), erythromycin $(15 \mu \mathrm{g})$ (Liofil Chem, Italy) and tetracycline (30 $\mu \mathrm{g}$ ) (Liofil Chem, Italy), in order to ascertain identities of similarcharacteristic isolates by differentiating them on the basis of antibiotic susceptibilities. The standard agar diffusion method using antibiotic discs, according to the Clinical and Laboratory Standards Institute (CLSI) guidelines ${ }^{21}$ was used:

A few distinct colonies of each isolate or test organism growing on a nutrient agar plate in previous $24 \mathrm{~h}$ were transferred with a sterile loop into $5 \mathrm{ml}$ of sterile water in a test tube. The suspension was thoroughly mixed with a spin mixer and adjusted to a turbidity of approximately $10^{6} \mathrm{cfu} / \mathrm{ml}$, using the $0.5 \mathrm{McF}$ arland standard. The suspension was then evenly spread on the surface of an over-dried Mueller Hinton agar plate with a sterile cotton tipped applicator (Sterilin Ltd, Middlesex, UK). The inoculated plates were incubated at $37{ }^{\circ} \mathrm{C}$ for $20 \mathrm{~min}$ for acclimatization and growth of the inoculum. The antibiotic discs were then lightly but firmly pressed onto the surface of the agar, equidistant to each other using sterile forceps. The plates were refrigerated at $4{ }^{\circ} \mathrm{C}$ for $30 \mathrm{~min}$ to permit diffusion of the antibiotics, and afterwards incubated at $37^{\circ} \mathrm{C}$ for 18 to $24 \mathrm{~h}$. S. aureus NCTC 6571, Bacillus subtilis NCTC 8263, E. coli ATCC 25922, and $P$. aeruginosa ATCC 10145 were used as control strains. The diameters of zones of inhibition were thereafter measured in duplicate tests, and interpreted according to the CLSI manual. ${ }^{21}$

\section{Determination of antimicrobial activities of T. cacao pod husk ash (CPHA) extract lotion formulations}

Antimicrobial activities of CPHA-extract lotion formulations (A, $\mathrm{B}, \mathrm{C}$, and D; Table 2) and of a comparator product, Neo-Medrol ${ }^{\circledR}$ after-shave lotion (Pfizer Inc. USA; containing $1.75 \mathrm{mg} / \mathrm{ml}$ neomycin sulphate as active principle) as positive control were determined against bacterial isolates from the after-shave facial bumps of volunteer subjects and reference organisms namely: $S$. aureus NCTC 6571, B. subtilis NCTC 8263, P. aeruginosa ATCC 10145, and E. coli ATCC 25922, using the agar-well diffusion assay as follows. Twenty milliliters of melted and cooled nutrient agar plates were seeded with $0.2 \mathrm{ml}$ (approx. $1 \times 10^{8}$ cells per $\mathrm{ml}$ ) of an overnight nutrient broth culture of each test organism and allowed to set. Three equidistant 7-mm diameter wells were cut into the plates with a sterile cup borer and $100 \mu$ of each lotion sample for testing was pipetted into 
separate agar wells such that each of the control and the formulated CPHA-extract lotion samples challenged each organism in duplicate experiments. The test products were allowed one hour to diffuse into the agar, and the plates were incubated at $37{ }^{\circ} \mathrm{C}$ for $24-48 \mathrm{~h}$. The inhibition zone diameters were thereafter measured.

\section{Preservative efficacy testing}

Preservative efficacy evaluation was carried out on two CPHAextract lotion formulations ( $\mathrm{B}$ and $\mathrm{C}$; Table 2) that earlier showed superior desirable qualities, using 4 test organisms namely: S. aureus NCTC 6571, P. aeruginosa ATCC 10145, Candida pseudotropicalis NCYC 6, and Candida albicans (an isolate obtained from the Department of Microbiology, OAU, Ile-Ife, Nigeria), according to compendium procedure. ${ }^{22}$ An overnight nutrient agar slope culture of the bacterial strains and an overnight Sabouraud dextrose agar slope culture of the yeast strains was washed, respectively, with $0.1 \%$ peptone water and diluted serially with same medium to provide the test inoculums. Duplicate test lotion samples $(9.9 \mathrm{ml}$ each) dispensed in sterile MacCartney bottles were inoculated with $0.1 \mathrm{ml}$ inoculum of one of the four challenge organisms, respectively, such that each 10.0 $\mathrm{ml}$ inoculated sample contained approx. $10^{6}$ colony forming units per milliliter $(\mathrm{cfu} / \mathrm{ml})$ of the inoculated cells, respectively. Peptone water in MacCartney bottles $(0.1 \%$; $9.9 \mathrm{ml})$ was also inoculated with $0.1 \mathrm{ml}$ of each test organism, respectively, as positive controls; while $10 \mathrm{ml}$ samples of each lotion formulation dispensed in MacCartney bottles, which were not inoculated with any organism, were used in parallel experiments as negative controls. Each test sample was shaken for uniform distribution and stored at the ambient temperature $\left(29 \pm 2^{\circ} \mathrm{C}\right)$ until periodic sampling times. At each sampling time (namely: 0, 6, $48 \mathrm{~h} ; 7,14$, and 28 days), $0.1 \mathrm{ml}$ of the inoculated lotion sample (or control), well mixed, was introduced into $9.9 \mathrm{ml}$ of $0.1 \%$ peptone water containing $1 \%$ Tween $80,{ }^{22}$ mixed thoroughly by vigorous shaking, and further serially diluted 1 in 100 aseptically with sterile water. $0.5 \mathrm{ml}$ aliquots of the latter dilution were then plated in duplicate onto sterile nutrient agar plates for bacteria, and Sabouraud dextrose agar plates for yeasts, and incubated aerobically at $37{ }^{\circ} \mathrm{C}$ for $24 \mathrm{~h}$, and $25^{\circ} \mathrm{C}$ for $48 \mathrm{~h}$, respectively. $0.5 \mathrm{ml}$ aliquot dilutions of the positive and negative control preparations were similarly plated out at $0 \mathrm{~h}$ along with the challenged products. The average number of colony forming units recovered of each test organism following the respective incubation periods was determined.

\section{Data analysis}

The data were subjected to descriptive (mean, range, standard error of mean; SEM) and inferential statistics namely, $t$-test, analysis of variance (ANOVA) and $\mathrm{F}$ test to determine significance of differences between compared means.

\section{Results}

\section{Stability properties of CPHA extract lotion formulations}

\section{Emulsion type, consistency and stability}

Regardless of which CPHA extract and its concentration (methanolic 2.5 or $5.0 \%$; or aqueous $4.0 \% \mathrm{w} / \mathrm{v}$ ) was used for preparation, preliminary formulations of CPHA extract emulsionlotion containing $5-25 \% \mathrm{w} /{ }_{\mathrm{w}}$ of shea butter (PF 1-5, 9, and 10; Table 1) were pourable liquid oil-in-water $(\mathrm{o} / \mathrm{w})$ emulsions, and redispersible on creaming (hence generally stable) immediately and within $1 \mathrm{~h}$ after preparation. But the other formulations containing $30-40 \% \mathrm{w} /{ }_{\mathrm{w}}$ shea butter (PF 6-8 and 11-14; Table 1) were viscous, not pourable and some of them congealed into semisolid consistency, prone to breaking when agitated. Pourable preliminary formulations containing 15-25 $\%{ }^{\mathrm{w} /} /$ of shea butter and made without Tween $80^{\circledR}$ and Span $80^{\circledR}$ (nonionic emulsifiers: PF 3-5; Table 1) exhibited little or no creaming over $24 \mathrm{~h}$ and were better in other stability characteristics during initial 7 days after preparation compared to the pourable formulations containing the emulsifiers (PF 9-11; Table 1). In summary, 20 and $25 \% \mathrm{w} /$ w shea butter concentrations used for CPHA-extract lotion formulation yielded the most desirable lotion consistency: showing no cracking, minimal creaming and redispersibility. The CPHA-extract lotion formulation A (Table 2) exhibited a strong alkaline $\mathrm{pH}$ value (11.55 \pm 0.13 ), which was lower than that of neat CPHA (methanolic) extract aqueous solution $(5 \% \mathrm{w} / \mathrm{v} ; \mathrm{pH}=12.98 \pm 0.03)$. However, on incorporation of citrate buffer $(5 \% \mathrm{w} / \mathrm{v})$ into the formulations $(\mathrm{B}$, $\mathrm{C}$, and D; Table 2) the $\mathrm{pH}$ value was neutralized to about 7.0 (Table 3), making them more suitable for topical application. ${ }^{23}$ Also, the presence of methyl cellulose ( 2 and $3 \% \mathrm{w} / \mathrm{v}$ ) in the lotion formulations (C and D, respectively; Table 2) increased their viscosity, resulting in considerable decrease in their creaming over time compared to formulations $\mathrm{A}$ and $\mathrm{B}$ that did not contain the viscosity imparting agent.

Table 3 Physicochemical stability properties of T. cacao pod husk ash (CPHA) extract lotion formulations

\section{Formulation ID/ Sampling time}

\begin{tabular}{|c|c|c|c|c|c|c|c|c|}
\hline & A & & & & B & & & \\
\hline Physicochemical stability indicators* & Day I & Wk I & Wk 2 & Wk 4 & Day I & Wk I & Wk 2 & Wk 4 \\
\hline $\mathrm{pH}$ & $11.6 \pm 1.0$ & $11.9 \pm 0.5$ & $11.9 \pm 0.7$ & $|2| \pm 0.8$. & $6.7 \pm 0.7$ & $6.7 \pm 0.7$ & $6.8 \pm 0.8$ & $7.1 \pm 0.6$ \\
\hline Viscosity (cP) & $2.5 \pm 1.0$ & $3.0 \pm 2.0$ & $3.5 \pm 2.0$ & $2.5 \pm 2.0$ & $4.5 \pm 1.0$ & $6.5 \pm 1.0$ & $6.5 \pm 1.0$ & $5.0 \pm 1.0$ \\
\hline Creaming (\%) & 0 & $40 \pm 2$ & $55 \pm 3$ & $62 \pm 3$ & 0 & $32 \pm 2$ & $35 \pm 2$ & $37 \pm 3$ \\
\hline \multirow[t]{2}{*}{ Droplet diameter $(\mu \mathrm{m})$} & $3.2 \pm 2.6$ & $5.0 \pm 3.9$ & $6.9 \pm 4.8$ & $8.0 \pm 5.7$ & $3.2 \pm 3.6$ & $4.7 \pm 2.7$ & $6.6 \pm 4.0$ & $7.8 \pm 3.6$ \\
\hline & C & & & & D & & & \\
\hline Physicochemical stability indicators* & Day I & Wk I & Wk 2 & Wk 4 & Day I & Wk I & Wk 2 & Wk 4 \\
\hline $\mathrm{pH}$ & $6.0 \pm 0.9$ & $7.3 \pm 0.4$ & $7.3 \pm 0.7$ & $7.2 \pm 0.5$ & $6.9 \pm 0.8$ & $7.0 \pm 0.5$ & $7.4 \pm 0.9$ & $7.4 \pm 0.9$ \\
\hline Viscosity (cP) & $7.0 \pm 1.0$ & $11.0 \pm 1.0$ & $12.0 \pm 1.0$ & $11.0 \pm 2.0$ & $40.0 \pm 1.0$ & $35.0 \pm 1.0$ & $30.0 \pm 1.0$ & $28.0 \pm 1.0$ \\
\hline
\end{tabular}


Table Continued.

\begin{tabular}{|c|c|c|c|c|c|c|c|c|}
\hline \multirow[b]{2}{*}{ Creaming (\%) } & \multicolumn{8}{|c|}{ Formulation ID/ Sampling time } \\
\hline & 0 & $<5$ & $5 \pm 1$ & $7 \pm 1$ & 0 & 0 & 0 & $<5$ \\
\hline Droplet diameter $(\mu \mathrm{m})$ & $3.1 \pm 4.7$ & $4.0 \pm 3.9$ & $7.8 \pm 5.9$ & $8.8 \pm 4.2$ & $3.8 \pm 3.7$ & $3.5 \pm 2.9$ & $6.3 \pm 4.6$ & $6.8 \pm 5.6$ \\
\hline
\end{tabular}

Key:

Formulation ID: Identity code of lotion formulation

*: $\mathrm{pH}$ and droplet-size data are expressed as Mean $\pm \mathrm{SEM}$; Viscosity data indicate Mean \pm Range; Creaming data indicates the cream-phase volume ratio, CVR (Vu/Vo) converted to percentage (\%) unit

$0: 0 \%$ Creaming means, no creaming occurred in the lotion samples

\section{Results of accelerated stability tests}

In the $\mathrm{B}, \mathrm{C}$, and $\mathrm{D}$ lotion formulations, centrifugal force at 1000 or $5000 \mathrm{rpm}$ lasting 30 or $60 \mathrm{~min}$ caused oil-phase separation of similar severity $(\mathrm{p}>0.05)(\leq 10 \%$; Figure (1B-1D) while a high proportion $(55-100 \%)$ of the emulsion phase (i.e. stable emulsified oil) was yet maintained in each; indicating that $\mathrm{MC}$ present at 2 or $3 \% \mathrm{w} / \mathrm{v}$ in $\mathrm{C}$ and $\mathrm{D}$ compared to its absence in B formulations (Table 2) caused no significant difference. Presence of MC made some difference, however, in products $\mathrm{C}$ and $\mathrm{D}$ compared to those without it ( $\mathrm{A}$ and $\mathrm{B}$ ) where, in A (66-76 \%) and in B (10-35\%) the aqueous-phase creaming-range was significantly higher $(\mathrm{p}<0.05)$ than the corresponding range of values for the $\mathrm{MC}$-containing formulations $(\mathrm{C}$ and $\mathrm{D} ; 0-10 \%$ in each, respectively). The creaming process was reversed by shaking; hence it was interpreted as only a mild manifestation of instability compared against oil-separation that was not reversible by shaking. Compared to their original viscosity values, the $\mathrm{B}$ and $\mathrm{C}$ formulations subjected to freeze-thaw temperature cycling stress demonstrated a significant decrease $(p<0.05)$ of their viscosities following the stressing cycle; while the mean droplet size of each formulation increased (but not significantly; $p>0.05$ ) due to the accelerated stability test. There was, however, no significant difference found in $\mathrm{pH}$ values of the formulations as a result of the temperature cycling stress $(p>0.05)$ (Table 4).

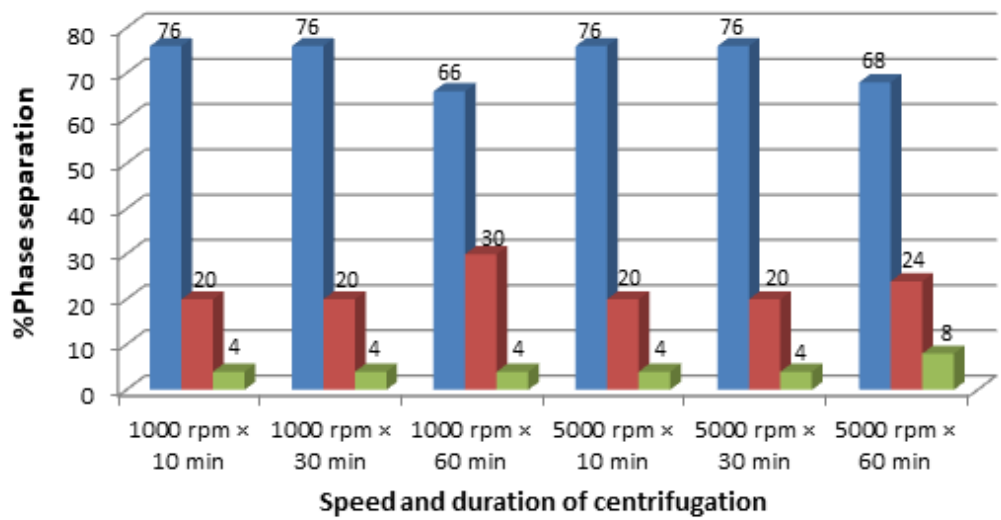

aqueous Emulsion ail

Figure IA Relative proportions of separated emulsion phases in CPHA-extract lotion A formulation following graded centrifugal forces.

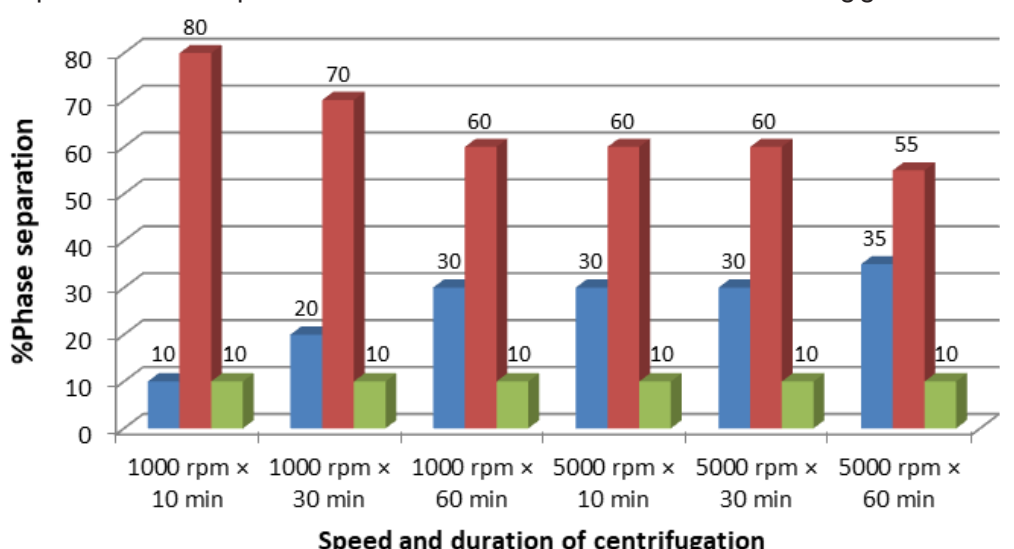

Speed and duration of centrifugation

\author{
aqueous Emulsion Oil
}

Figure IB Relative proportions of separated emulsion phases in CPHA-extract lotion B formulation following graded centrifugal forces. 


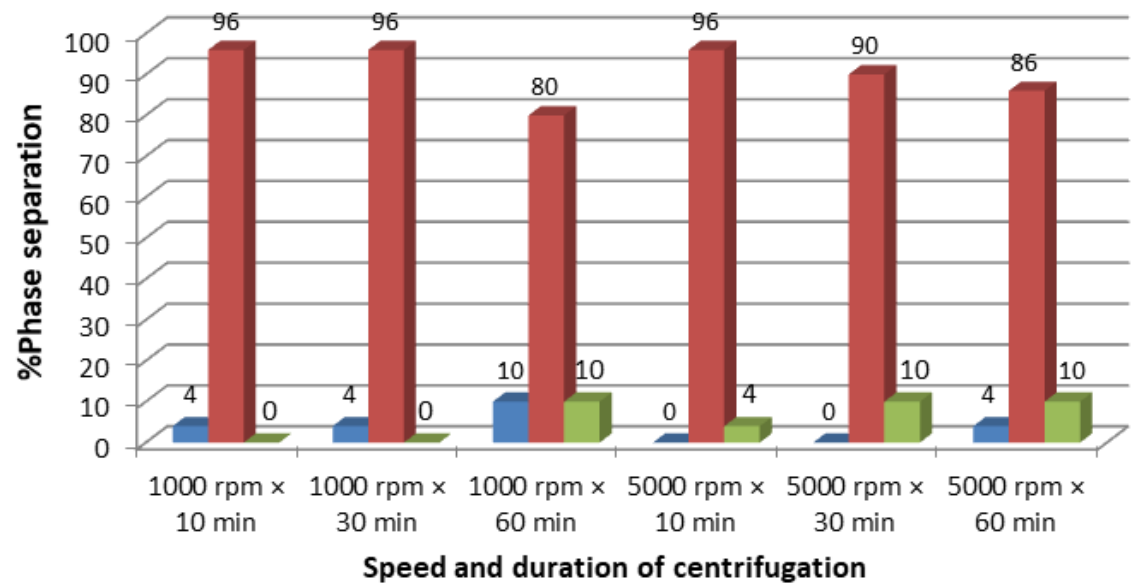

aqueous Emulsion Oil

Figure IC Relative proportions of separated emulsion phases in CPHA-extract lotion C formulation following graded centrifugal forces.

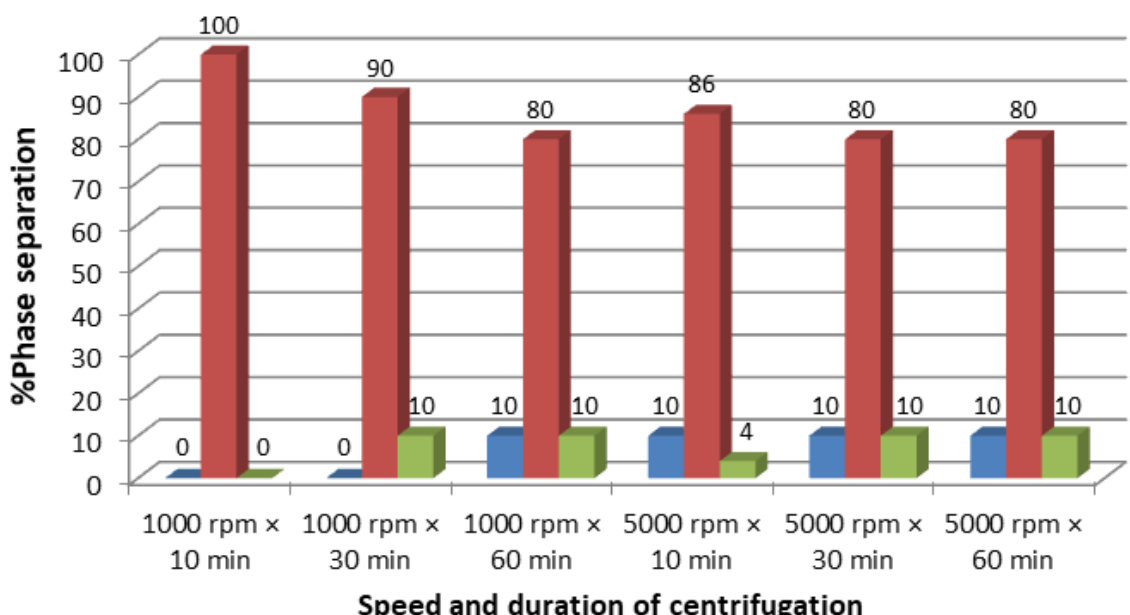

Speed and duration of centrifugation

aqueous Emulsion $n$ Oil

Figure ID Relative proportions of separated emulsion phases in CPHA-extract lotion D formulation following graded centrifugal forces.

Table 4 Effect of freeze-thaw temperature cycling on stability of selected CPHA-extract lotion formulations

\begin{tabular}{|c|c|c|c|c|c|c|}
\hline \multirow[b]{3}{*}{ Sampling Time } & \multicolumn{6}{|c|}{ Formulation Code/ Physical Stability Indicators/ Stability data* } \\
\hline & \multicolumn{3}{|l|}{ B } & \multicolumn{3}{|l|}{ C } \\
\hline & $\mathrm{pH}$ & Droplet diameter $(\mu \mathrm{m})$ & Dynamic viscosity (cP) & $\mathrm{pH}$ & Droplet diameter $(\mu \mathrm{m})$ & Dynamic viscosity $(\mathrm{cP})$ \\
\hline $\begin{array}{l}\text { Before freeze- } \\
\text { thaw cycling }\end{array}$ & $6.7 \pm 0.7$ & $3.2 \pm 2.8$ & $4.5 \pm 0.5$ & $6.0 \pm 0.9$ & $3.1 \pm 3.9$ & $7.0 \pm 1.0$ \\
\hline $\begin{array}{l}\text { After freeze- } \\
\text { thaw cycling }\end{array}$ & $7.1 \pm 0.4$ & $5.8 \pm 3.3$ & $2.0 \pm 0.5$ & $7.2 \pm 0.6$ & $6.1 \pm 2.2$ & $2.2 \pm 1.0$ \\
\hline
\end{tabular}

Key:

*: $\mathrm{pH}$ and droplet-size data are expressed as Mean \pm SEM;Viscosity data indicate Mean \pm Range

Incidence and susceptibility profile of volunteers' after-shave bump swab microbes

Each of the 15 volunteers' after-shave bump swabs gave microbial growth on nutrient agar and mannitol salt agar, but no growth on
Sabouraud dextrose agar. Three or four bacterial isolates per volunteer were recovered from the shaving bump swab sampling process; and 51 isolates in all, which exhibited different cultural and morphological characteristics, were obtained from the 15 volunteers, namely: 30 isolates that were presumptive-positive identified as Staphylococci 
species (in that they fermented mannitol, growing on the agar medium as yellow colonies surrounded by yellow zone). Two isolates were Gram-positive bacilli, while all others were Gram-positive cocci that appeared in clusters or tetrads. The swab-sourced bacterial isolates thus represented the potential pathogens for secondary infection in the volunteers' shaving bump cases. Fourteen (i.e. approx. 47\%) of the 30 presumptive staphylococcal strains showed sensitivity and susceptibility to CPHA-extract lotions (Table 5). Biochemical testing (catalase, coagulase and modified oxidase tests) revealed that all the 14 coccal isolates were catalase-positive (showing ability to evolve gas), 6 of which tested positive to slide coagulase test (i.e. visible clumping and agglutination) and so were confirmed as $S$. aureus with bound coagulase enzymes. Eleven (i.e. $\approx 37 \%$ ) of the 30 presumptive staphylococcal isolates tested positive to tube coagulase test (showing clotting within $4 \mathrm{~h}$ ), and these were identified as $S$. aureus with free coagulase enzymes. ${ }^{24}$ None of the isolates turned the deep brown colour of modified oxidase reagent to dark blue or purple colour within $10 \mathrm{~s}$, indicating that they all were staphylococci, not micrococci. ${ }^{19,25}$ Concerning susceptibility to selected antibiotics, one strain (the S.14b) of the 30 presumptive staphylococcal isolates was mildly resistant to ciprofloxacin, 5 (the S.1b, S.3a, S.5d, S.10Ac, and S.15b) were resistant to tetracycline, and 5 (the S.5a, S.5b, S.5c, S.6a, and S.12b) were resistant to erythromycin; while 29,25 , and 25 of the isolates were susceptible to ciprofloxacin, tetracycline, and erythromycin, respectively (Table 5). Among the comparator organisms studied, $P$ aeruginosa was found resistant to both tetracycline and erythromycin. Overall, ciprofloxacin demonstrated the widest activity spectrum (Table 5). These results have value for possible antibiotic treatment.

Table 5 Susceptibility of facial-swab microbial Isolates and type organisms to antibacterial activities of selected antibiotics, CPHA-extract lotion formulations and control

\begin{tabular}{|c|c|c|c|c|c|c|c|c|}
\hline \multirow{3}{*}{$\begin{array}{l}\text { Test organism/ facial- } \\
\text { swab isolate ("S") }\end{array}$} & \multicolumn{8}{|c|}{ Test product or antibiotic / Inhibition zone diameter $(\mathbf{m m}) *$} \\
\hline & \multirow{2}{*}{$\begin{array}{l}\text { Ciprofloxacin } \\
5 \boldsymbol{\mu g}\end{array}$} & \multirow{2}{*}{$\begin{array}{l}\text { Tetracycline } \\
30 \mu \mathrm{g}\end{array}$} & \multicolumn{5}{|c|}{ Erythromycin } & \multirow[t]{2}{*}{$\begin{array}{l}\text { Control after-shave } \\
\text { lotion (Neo-Medrol })^{-}\end{array}$} \\
\hline & & & $15 \mu g$ & A & B & C & D & \\
\hline S. aureus NCTC 657I & $25.0 \pm 0.5$ & $25.0 \pm 0.5$ & $27.0 \pm 0.5$ & 0 & $20 \pm 1$ & $13 \pm 1$ & $12 \pm 1$ & $29 \pm 1$ \\
\hline B. subtilis NCTC 8263 & $23.0 \pm 0.5$ & $15.0 \pm 0.5$ & $23.0 \pm 0.5$ & 0 & $20 \pm 1$ & $13 \pm 1$ & 0 & $23.5 \pm 0.5$ \\
\hline P. aeruginosa ATCC I0I45 & $33.0 \pm 0.5$ & 0 & 0 & 0 & $20 \pm 1$ & $13 \pm 1$ & $12 \pm 1$ & $25.5 \pm 0.5$ \\
\hline E. coli ATCC 25922 & $27.0 \pm 0.5$ & $16.0 \pm 0.5$ & 0 & 0 & 0 & 0 & 0 & 0 \\
\hline S.Ib & $29.0 \pm 0.5$ & 0 & $10.0 \pm 0.5$ & 0 & $12 \pm 1$ & $I I \pm I$ & $12 \pm 1$ & $24.5 \pm 0.5$ \\
\hline S.Ic & $28.0 \pm 0.5$ & $12.0 \pm 0.5$ & $23.0 \pm 0.5$ & 0 & $13 \pm 1$ & $14 \pm 1$ & $13 \pm 1$ & $22 \pm 1$ \\
\hline S.2b & $28.0 \pm 0.5$ & $23.0 \pm 0.5$ & $26.0 \pm 0.5$ & 0 & $14.5 \pm 0.5$ & $\mid 4 \pm 1$ & 0 & $24.5 \pm 0.5$ \\
\hline S.3a & $22.0 \pm 0.5$ & 0 & $18.0 \pm 0.5$ & 0 & $15 \pm 1$ & $15 \pm 1$ & $\mid 4 \pm 1$ & $29 \pm 1$ \\
\hline S.3c & $25.0 \pm 0.5$ & $18.0 \pm 0.5$ & $25.0 \pm 0.5$ & 0 & $12 \pm 1$ & 0 & 0 & 0 \\
\hline S.5a & $23.0 \pm 0.5$ & $19.0 \pm 0.5$ & 0 & 0 & $12 \pm 1$ & $12 \pm 1$ & 0 & $25.5 \pm 0.5$ \\
\hline S.5b & $31.0 \pm 0.5$ & $22.0 \pm 0.5$ & 0 & 0 & $12.5 \pm 1$ & $12 \pm 1$ & 0 & $26.5 \pm 0.5$ \\
\hline S.5c & $25.0 \pm 0.5$ & $19.0 \pm 0.5$ & 0 & 0 & $18 \pm 1$ & $12 \pm 1$ & 0 & $29.5 \pm 0.5$ \\
\hline S.5d & $28.0 \pm 0.5$ & 0 & $25.0 \pm 0.5$ & 0 & 0 & 0 & 0 & $20 \pm 1$ \\
\hline S.6a & $28.0 \pm 0.5$ & $20.0 \pm 0.5$ & 0 & 0 & 0 & 0 & 0 & $29.5 \pm 0.5$ \\
\hline S.6b & $24.0 \pm 0.5$ & $19.0 \pm 0.5$ & $24.0 \pm 0.5$ & 0 & 0 & 0 & 0 & $26 \pm 1$ \\
\hline S.7a & $23.0 \pm 0.5$ & $24.0 \pm 0.5$ & $26.0 \pm 0.5$ & 0 & 0 & 0 & 0 & $28 \pm 1$ \\
\hline S.7b & $25.0 \pm 0.5$ & $20.0 \pm 0.5$ & $26.0 \pm 0.5$ & 0 & 0 & 0 & 0 & $25.5 \pm 0.5$ \\
\hline S.8a & $28.0 \pm 0.5$ & $28.0 \pm 0.5$ & $26.0 \pm 0.5$ & 0 & $14.5 \pm 0.5$ & $12 \pm 1$ & $12 \pm 1$ & $29 \pm 1$ \\
\hline S.8b & $26.0 \pm 0.5$ & $23.0 \pm 0.5$ & $25.0 \pm 0.5$ & 0 & 0 & 0 & 0 & $30 \pm 1$ \\
\hline S.8c & $27.0 \pm 0.5$ & $18.0 \pm 0.5$ & $21.0 \pm 0.5$ & 0 & 0 & 0 & 0 & $24.5 \pm 0.5$ \\
\hline S.9b & $31.0 \pm 0.5$ & $20.0 \pm 0.5$ & $24.0 \pm 0.5$ & 0 & $14 \pm 1$ & $12 \pm 1$ & $12 \pm 1$ & $28 \pm 1$ \\
\hline $5.9 c$ & $26.0 \pm 0.5$ & $19.0 \pm 0.5$ & $25.0 \pm 0.5$ & 0 & 0 & 0 & 0 & $22 \pm 1$ \\
\hline S.IOAa & $36.0 \pm 0.5$ & $28.0 \pm 0.5$ & $32.0 \pm 0.5$ & 0 & $12 \pm 1$ & 0 & 0 & $26 \pm 1$ \\
\hline S.IOAb & $28.0 \pm 0.5$ & $24.0 \pm 0.5$ & $25.0 \pm 0.5$ & 0 & 0 & 0 & 0 & $27.5 \pm 0.5$ \\
\hline
\end{tabular}


Table Continued..

Test product or antibiotic / Inhibition zone diameter $(\mathrm{mm})^{*}$

\begin{tabular}{|c|c|c|c|c|c|c|c|c|}
\hline \multirow[t]{2}{*}{$\begin{array}{l}\text { Test organism/ facial- } \\
\text { swab isolate ("S") }\end{array}$} & \multirow{2}{*}{$\begin{array}{l}\text { Ciprofloxacin } \\
5 \mu g\end{array}$} & \multirow{2}{*}{$\begin{array}{l}\text { Tetracycline } \\
30 \mu g\end{array}$} & \multicolumn{5}{|c|}{ Erythromycin } & \multirow[t]{2}{*}{$\begin{array}{l}\text { Control after-shave } \\
\text { lotion (Neo-Medrol }()\end{array}$} \\
\hline & & & $15 \mu g$ & $\mathbf{A}$ & B & C & D & \\
\hline S.IOAC & $27.0 \pm 0.5$ & 0 & $27.0 \pm 0.5$ & 0 & $12 \pm 1$ & $\mid I \pm 1$ & $12 \pm 1$ & $26.5 \pm 0.5$ \\
\hline S.IIb & $27.0 \pm 0.5$ & $21.0 \pm 0.5$ & $29.0 \pm 0.5$ & 0 & 0 & 0 & 0 & $24.5 \pm 0.5$ \\
\hline S. $12 \mathrm{a}$ & $22.0 \pm 0.5$ & $20.0 \pm 0.5$ & $9.0 \pm 0.5$ & 0 & 0 & 0 & 0 & $22 \pm 1$ \\
\hline S. $12 b$ & $28.0 \pm 0.5$ & $25.0 \pm 0.5$ & 0 & 0 & 0 & 0 & 0 & $25 \pm 1$ \\
\hline S.12d & $25.0 \pm 0.5$ & $25.0 \pm 0.5$ & $8.0 \pm 0.5$ & 0 & $15 \pm 1$ & $13 \pm 1$ & $12 \pm 1$ & $27 \pm 1$ \\
\hline S.13a & $27.0 \pm 0.5$ & $22.0 \pm 0.5$ & $25.0 \pm 0.5$ & 0 & $14 \pm 1$ & 0 & 0 & $20 \pm 1$ \\
\hline S.I3b & $27.0 \pm 0.5$ & $22.0 \pm 0.5$ & $25.0 \pm 0.5$ & 0 & 0 & 0 & 0 & $21.6 \pm 0.5$ \\
\hline S.14b & $9.0 \pm 0.5$ & $23.0 \pm 0.5$ & $27.0 \pm 0.5$ & 0 & 0 & 0 & 0 & $21 \pm 1$ \\
\hline$S .15 b$ & $22.0 \pm 0.5$ & 0 & $23.0 \pm 0.5$ & 0 & 0 & 0 & 0 & $20 \pm 1$ \\
\hline S. $15 \mathrm{c}$ & $30.0 \pm 0.5$ & $17.0 \pm 0.5$ & $23.0 \pm 0.5$ & 0 & 0 & 0 & 0 & $28 \pm 1$ \\
\hline
\end{tabular}

Key:

*: Data indicates the Mean \pm Range of inhibition zone diameter measurements $(\mathrm{mm})$

0: Organism was not inhibited

S: Facial swab isolate code:The figure (I-I5) of the code indicates serial number for the volunteer-subjects I-I5, while the alphabets (a, b, c, d, Aa, Ab, or Ac) indicate Isolate-identification letters

The lotion formulations:A, B, C, and D are as described in Table 2

\section{Antibacterial activities of CPHA extract lotion formulations}

The CPHA-extract lotion formulations B, C, and D demonstrated inhibitory activities against the reference bacterial organisms: $S$. aureus NCTC 6571 and P. aeruginosa ATCC 10145, while the formulations $\mathrm{B}$ and $\mathrm{C}$ also showed activities against $B$. subtilis NCTC 8263. However, formulations A and D showed no activity against B. subtilis NCTC 8263, and E. coli ATCC 25922 was not sensitive to the antibacterial activities of all the formulations (A, B, C, or D; Table 5). The CPHA-extract lotions B, C, and D also demonstrated inhibitory activities against some (less than a half) of the facial swab isolates, while formulation A showed no activity against them all. On the other hand, the comparator after-shave lotion product, NeoMedro ${ }^{\circledR}$ showed activities against most of the isolates (Table 5) and demonstrated significantly greater $(p<0.05)$ antibacterial effects than those of the CPHA extract lotion formulations against the isolates and reference organisms.

\section{Selection of optimal formulations of CPHA-extract lotion}

From consideration of its superior physical stability (Fig. 1), antimicrobial activities (Table 5) and preferable $\mathrm{pH}$ values (Table 3), the CPHA-extract lotion B was selected as better than the lotion
A. Similarly the lotion $\mathrm{C}$ which demonstrated a relatively broader scope of antibacterial activities against test organisms (Table 5), and was more readily pourable due to its lower viscosity (Table 3) and contained a lower MC proportion (Table 1) hence with better promise of cost-effectiveness in scale-up production than the lotion $\mathrm{D}$, was preferably selected. The $\mathrm{B}$ and $\mathrm{C}$ lotion formulations were thus selected as the optimal formulations of CPHA-extract lotion that demonstrated more desirable qualities than the others.

\section{Results of preservative efficacy tests}

Results of preservative efficacy tests on the CPHA-extract lotion products $\mathrm{B}$ and $\mathrm{C}$ (Table 6) showed that the yeast cells (Candida) were more vulnerable than bacterial cells to the preservative in both formulations, in that no growths of C. pseudotropicalis or C. albicans were recovered from the tested products throughout the study. On the other hand, viable cells of $P$. aeruginosa $(\mathrm{Pa})$ or $S$. aureus $(\mathrm{Sa})$ were found in some of the lotion samples under testing until the $6^{\text {th }}$ and $48^{\text {th }}$ $\mathrm{h}\left(\mathrm{Pa}\right.$ in product $\mathrm{C}$ and $\mathrm{Sa}$ in product $\mathrm{B}$, respectively), or until the $7^{\text {th }}$ day of sampling ( $\mathrm{Sa}$ in product $\mathrm{C}$ ). None of the inoculated organisms was, however, recovered from the formulation samples from Day 14 forward (Table 6). And whereas all positive control experiments demonstrated growths confirming each test organism's viability, no organisms were recovered from all the negative control preparations that were not challenged with any test organisms. 
Table 6 Results of preservative efficacy tests on selected CPHA-extract lotion formulations

\begin{tabular}{|c|c|c|c|c|c|c|c|c|}
\hline \multirow[b]{3}{*}{ Sampling Time } & \multicolumn{8}{|c|}{ Formulation Code/ Challenge Organism/ Residual contaminants load (cfu/ml) } \\
\hline & \multicolumn{4}{|l|}{ B } & \multicolumn{4}{|l|}{ C } \\
\hline & S. aureus & P. aeruginosa & C. pseudotropicalis & C. albicans & S. aureus & P. aeruginosa & C. pseudotropicalis & C. albicans \\
\hline $\mathrm{Oh}$ & $4 \times 104$ & $3 \times 104$ & 0 & 0 & $4 \times 104$ & $6 \times 104$ & 0 & 0 \\
\hline $6 \mathrm{~h}$ & $4 \times 104$ & $2 \times 104$ & 0 & 0 & $4 \times 104$ & $2 \times 104$ & 0 & 0 \\
\hline $48 \mathrm{~h}$ & $4 \times 104$ & 0 & 0 & 0 & $2 \times 104$ & 0 & 0 & 0 \\
\hline 7th day & 0 & 0 & 0 & 0 & $1 \times 104$ & 0 & 0 & 0 \\
\hline I4th day & 0 & 0 & 0 & 0 & 0 & 0 & 0 & 0 \\
\hline 28th day & 0 & 0 & 0 & 0 & 0 & 0 & 0 & 0 \\
\hline
\end{tabular}

Key:

$0:$ No residual contaminant was recovered

\section{Discussion}

This study describes an investigation of soap-stabilized liquid emulsion (lotion) formulations produced by shea butter emulsification in aqueous solution of cocoa pod husk ash (CPHA) methanolic extract, having antibacterial properties and suitable for use as shaving bumps (Pseudofolliculitis barbae, PFB) treatment. It provides a valorized use of cocoa pod husk as well as an additional therapeutic option for PFB. On ashing of cocoa pod husk, its potassium and high sodium contents ${ }^{26}$ become available as the salt residues to react with free fatty acids in a vegetable oil or fat to produce soap that could serve as anionic surfactant in an emulsion preparation. ${ }^{27}$ This study has demonstrated the ability of aqueous solutions of the methanolic CPHA extract to emulsify shea butter and produce stable lotions, while the extract serves as an antibacterial agent for treatment of shaving bumps. Shaving creams, soaps and gels as well as after-shave lotions and balms are widely used by men as grooming products to obtain and maintain a clean shave and smooth face. The satisfactory physicochemical stability properties of the lotions $\mathrm{B}$ and $\mathrm{C}$ overall, selected as the most suitable for PFB treatment, are due to the lotion composition and component proportions. Shea butter is an established cosmetic ingredient that is included and well tolerated by users of all ages in a variety of skin treatment products. ${ }^{8,28}$ It serves (at $20 \% \mathrm{w} / \mathrm{w}$ concentration) as the oil phase giving a viscous-liquid consistency to the oil-in-water emulsion-lotion system at the ambient temperature. It was used in the formulations also for its emollient effect, ${ }^{7,9}$ which should cushion the abrasive effect of shaving on facial skin and could also aid healing of abrasions. The enhanced viscosity of lotion $\mathrm{C}$ due to the presence of methyl cellulose $(2 \% \mathrm{w} / \mathrm{v})$ in its formula would aid its application by preventing its running off from the application site on the skin surface. Furthermore the CPHA extract, as the continuous aqueous phase, also contains potash in solution, which offers both astringent and deodorant properties. ${ }^{29}$ The methanolic extract of CPHA, employed in the formulations, had previously demonstrated superior antimicrobial activities ${ }^{16}$ and was thus preferred to the aqueous extract, in order to ensure better antibacterial effects. Consequently, the selected formulations (B and C) demonstrated inhibitive activities against proliferation of the skin commensal, $S$. aureus and other organisms used in the study, which could become important for opportunistic secondary infection in PFB cases. The $\mathrm{pH}$ of the formulations is neutral-buffered to guarantee their compatibility with skin surface fluid and preclude irritancy. Finally, the results of preservative efficacy testing of lotions meet the pharmacopoeial requirement for non-sterile topical pharmaceutical preparations. ${ }^{22}$ The lotions as an emulsion system should be stored in a cool environment avoiding extremes of temperature fluctuation, in order to support and maintain their consistency and stability qualities.

\section{Acknowledgments}

None.

\section{Conflicts of interest}

Authors declare that there is no conflict of interest.

\section{References}

1. Coley MK, Alexis AF. Dermatologic conditions in men of African ancestry, Expert Rev Dermatol. 2009;4(6):595-609.

2. Ogunbiyi A. Pseudofolliculitis barbae; current treatment options. Clin Cosmet Invest Dermatol. 2019;12:241-247.

3. Daniel A, Gustafson CJ, Zupkosky PJ, et al. Shave frequency and regimen variation effects on the management of pseudofolliculitis barbae. J Drugs Dermatol. 2013;12(4):410-418.

4. Gray J, McMichael AJ, Michael M. Pseudofolliculitis barbae: understanding the condition and the role of facial grooming. Int J Cosmet Sci. 2016;38(Suppl 1):24-27.

5. Djekota C, Diouf D, Sane S, et al. Morphological characterization of shea tree (Vitellaria paradoxa subsp. paradoxa) populations in the region of Mandoul in Chad. Int J Biodivers Conserv. 2014;6(2):184-193.

6. Athar M, Nasir SM. Taxonomy perspective of plant species yielding vegetable oils used in cosmetics and skin care products. Afr J Biotech. 2005;4(1):36-44.

7. Glew D, Lovett PN. Life cycle analysis of shea butter use in cosmetics: from parklands to product, low carbon opportunities. J Clean Prod. 2014;68:73-80.

8. Essengue-Belibi S, Stechschulte D, Olson N. The use of shea butter an an emollient for eczema. J Allergy Clinical Immunol. 2009;123(2):145-148.

9. Oyedele AO. The skin tolerance of shea fat employed as excipient in topical preparations. Nig J Nat Prod Med. 2002;6:26-30.

10. Prabhakaran-Nair KP. The agronomy and economy of important tree crops of the developing world. Chapter 5: Cocoa (Theobroma cacao L.), Elsevier Inc. 2010:131-180.

11. Adi-Dako O, Ofori-Kwakye K, Manso SF, et al. Physicochemical and antimicrobial properties of cocoa pod husk pectin intended as a versatile pharmaceutical excipient and nutraceutical. J Pharmaceut. 2016: ID 7608693 . 
12. Osonwa UE. Physico-technical and release properties of some drug granulations containing Theobroma cacao polysaccharide as an adhesive. Ph.D. Thesis 2011; Department of Biochemistry, Faculty of Biological Sciences, University of Nigeria, Nsukka Nigeria. 2011.

13. Ordu JI, Ocheme EJ. Evaluation of the disintegrant and dissolution properties of powder and cellulose obtained from cocoa pod husk on paracetamol tablets. Scientia Africana. 2011;10(2):9-17.

14. Abdul-Karim A, Azlan A, Ismail A, et al. Phenolic composition, antioxidant, anti-wrinkles and tyrosinase inhibitory activities of cocoa pod extract. BMC Complement Altern Med. 2014;14:1-13.

15. Abdul-Karim A, Azlan A, Ismail A, et al. Efficacy of cocoa pod extract as antiwrinkle gel on human skin surface. J Cosmet Dermatol. 2016;15(3):283-295.

16. Akinrotohun HO, Oyedele AO, Igbeneghu OA, et al. Studies on the physicochemical and antimicrobial properties of Theobroma cacao pod husk ash extract. J Pharma Pharmaceut. 2020;7(1):17-24.

17. Oyedele AO. Fluid emulsion base potential of shea butter. J Pharm Biores. 2016;13(2):103-113.

18. Gibson LF, Khoury JT. Storage and survival of bacteria by ultra-freeze. Lett Appl Microbiol. 1986;3:127-129.

19. Koneman EW. Koneman's color atlas and textbook of diagnostic microbiology. Lippincott Williams and Wilkins, Washington USA, 2006.

20. Barrow GI, Feltham RKA. Cowan and Steel's Manual for the Identification of Medical Bacteria. Cambridge; Cambridge University Press, 1993.

21. Clinical and Laboratory Standards Institute (CLSI) Guidelines. Performance standards for antimicrobial disk tests: Approved standard. CLSI document M02-A11 (11 ${ }^{\text {th }}$ ed., Vol. 32). 950, West Valley road, Suite 2500, Wayne, Pennsylvania 19087 USA, 2012.
22. British Pharmacopoeia. British Pharmacopoeia Office. MHRA 151 Buckingham Palace Road, London, 2013.

23. Schmid-Wendtner M, Korting HC. $p H$ and skin care, $A B W$ Wissenschaftsverlag GmbH, 10707 Berlin, Germany. 2007. p. 15-97.

24. Kateete DP, Kimani CN, Katabazi FA, et al. Identification of Staphylococcus aureus: DNase and mannitol salt agar improve the efficiancy of the tube coagulase test. Ann. Clin. Microbiol. Antimicrob. 2010;9:23.

25. Kloos WE, Bannerman TL. Staphylococcus and Micrococcus. In: Manual of clinical microbiology, Murray PR, et al., editors. 282-298, ASM press, Washington DC, USA. 1995.

26. Bonvehí JS, Jordà RE. Constituents of Cocoa Husks. Z Naturforsch. 1998;53c:785-792.

27. Jayeola CO, Adebowale BA, Yahaya LE. Production of bioactive compounds from waste. In: Therapeutic, Probiotic, and Unconventional Foods, Chapter 18, Cocoa Research Institute of Nigeria (CRIN), Ibadan, Nigeria. 2018:317-340.

28. Goreja WG. Shea butter: The nourishing properties of Africa's best-kept secret. Amazing Herbs Press, New York, NY, USA, Chap. 3 "Historical Uses of Shea Butter" 2004:7-10.

29. Alzomor A K, Moharram A S, Mansour N. et al. Formulation and evaluation of potash alum as deodorant lotion and after shaving astringent as cream and gel. Int Curr Pharm J. 2014;3(2):228-233. 